Article

\title{
Probabilistic Prediction of Corrosion Damage of Steel Structures in the Vicinity of Roads
}

\author{
Monika Kubzova ${ }^{1, *(\mathbb{D})}$, Vit Krivy ${ }^{1}(\mathbb{D})$ and Katerina Kreislova ${ }^{2}(\mathbb{D}$ \\ 1 Department of Structures, Faculty of Civil Engineering, VSB-Technical University of Ostrava, \\ 70800 Ostrava-Poruba, Czech Republic; vit.krivy@vsb.cz \\ 2 SVUOM Ltd., U Mestanskeho Pivovaru 934/4, 17000 Prague 7, Czech Republic; kreislova@svuom.cz \\ * Correspondence: monika.kubzova@vsb.cz
}

Received: 7 November 2020; Accepted: 23 November 2020; Published: 25 November 2020

\begin{abstract}
The design, construction, and maintenance of steel structures must be carried out in a way that ensures they will be able to reliably operate for the whole duration of their planned service life. To ensure sufficient durability, it is necessary to determine and evaluate the characteristics of the appropriate environment in which the structure will be placed. This submission focuses on the specific environment surrounding roads that are treated with de-icing salts during winter maintenance. It investigates the dependency between corrosive damage to the structure and the relevant parameters of the environment. Basic corrosive factors include temperature, relative humidity, deposition of chlorides and sulfur dioxide, precipitation, the $\mathrm{pH}$ of precipitation as well as many other parameters. An accurate estimate of corrosive damage requires an analysis of the long-term trends in concentrations of individual corrosive factors, while respecting their randomly varying attributes. The article, hence, introduces and evaluates stochastic prediction models that are based on long-term programs focusing on the evaluation of the corrosive aggressiveness of the environment, while taking into account random variations of the nature of the input parameters. The use of stochastic prediction models allows us to perform sensitivity analysis that can determine the impact of specific corrosive factors on the corrosive damage caused to the structure. The article is supplemented by sensitivity analysis focusing on an evaluation from the effects of the deposition of chlorides on the corrosive damage to steel bridge structures. The analysis was carried out using data obtained from experimental measurements of the deposition rates of chlorides in the vicinity of roads in the Czech Republic.
\end{abstract}

Keywords: durability; steel structures; corrosion aggressiveness; prediction models; de-icing salts

\section{Introduction}

Traffic, energy, and environmental infrastructure (including bridge structures) represent approximately $70 \%$ of the national property in European countries. Their operation, maintenance, and repairs require approximately $35 \%$ of the overall material and energy needs and produce roughly $30 \%$ of all waste and environmental burdens. The primary factors affecting the conditions of the operated bridge structures include not only natural changes to materials, hidden structural defects, and increased intensity of traffic but also degradation processes that occur in structural elements due to the environmental stress caused by the surrounding environment $[1,2]$. The negative impact of the degradation processes can be documented on the technical conditions of road bridges in the Czech Republic: out of the total of approximately 16,000 operated bridge structures in the Czech Republic, roughly 1000 are in a very poor or emergency condition [3-5].

Air pollution is one of the primary degradation factors that affect the required durability of bridge structures. Air pollution affects the degradation of most materials used in traffic infrastructure (for steel elements this is notably related to damage caused to the corrosion protection system, leading to 
corrosive damage). Air pollution can be caused by two sources: natural sources or human activities; the latter is becoming increasingly prevalent. The surroundings of roads with intense road traffic characteristically feature specific microclimatic conditions, notably including a higher concentration of settled dust particles and chloride ions from the de-icing salts used for winter maintenance.

Basic environmental parameters affecting degradation processes notably include temperature, air humidity, precipitation and its $\mathrm{pH}$, air pollution notably including the deposition of sulfur dioxide, nitrogen oxide and chlorides, dust particles, and others [6,7]. The degradation of the surfaces of steel structures is significantly influenced by two corrosion stimulators related to air pollution: the effects of sulfur dioxide and the depositing of chloride ions. The concentration of $\mathrm{SO}_{2}$ in the air reached its peak in the Czech Republic (similarly as elsewhere in Europe) in the seventies and eighties of the previous century. At that time, the air concentration of $\mathrm{SO}_{2}$ in the Czech Republic reached up to $200 \mu \mathrm{g} / \mathrm{m}^{3}[6,7]$. A significant drop in the concentration of $\mathrm{SO}_{2}$ was caused primarily by the introduction of desulfurizes in large industrial companies. Currently, the $\mathrm{SO}_{2}$ concentrations in the Czech Republic fluctuate at around $10 \mu \mathrm{g} / \mathrm{m}^{3}$. On the other hand, the amount of settled chloride ions in the vicinity of roads exhibits an opposite trend, with an increase caused by the higher intensity of road traffic. Chloride ions spread together with the aerosol from melting ice or dust to the surfaces of structures from chemical de-icing agents used during the winter maintenance of roads. The spread of chlorides is significant especially on a local scale, near the vicinity of roads, depending on the parameters of the surrounding environment, the quantity and nature of barriers located in the vicinity of the road, speed and intensity of traffic, etc. [8-10]. Experimental measurements carried out at selected bridge structures and in their surroundings called attention to the fact that the quantity of deposited chloride ions spread in the air is also significantly impacted by the design of the bridge structure and the topography of the surrounding terrain [11-13].

A good estimate for the corrosive behavior of metal in the atmosphere is one of the key parameters allowing the design of suitable measures (selection of a corrosion protection system, suitable dimensions for profiles, structural solutions that match the environmental conditions, functional maintenance system) that will allow for the reliable operation of load-bearing elements of the bridge structure for its whole planned service life. The corrosion aggressiveness of the atmospheres (the environment) is usually related to the value of expected corrosion losses. The effects of atmospheric corrosion can be described using a model that considers the environmental parameters that affect the corrosive behavior of metals in the following general form $[6,14,15]$ :

$$
\begin{gathered}
K=\sum\left\{K_{\text {wet }}, K_{d r y}\right\} \\
K_{d r y}=\sum\left\{T, R H, S O_{2}, \mathrm{NO}_{2}, \mathrm{O}_{3}, \mathrm{HNO}_{3}, \mathrm{PM}_{10}\right\} \\
K_{\text {wet }}=\sum\left\{\text { Rain }, \mathrm{H}^{+}\right\}
\end{gathered}
$$

where $K_{d r y}$ represents the set of effects of basic parameters for dry atmospheric deposition on the structure's surface and $K_{w e t}$ represents the set of effects of basic parameters for wet atmospheric deposition on the structure's surface.

The environment where the structure is located can be classified into one of several corrosion classes $\left(\mathrm{C} 1\right.$ to $\mathrm{CX}$ ) based on the corrosion rates, $r_{\text {corr }}$, measured after 1 year of exposure (whereas the pollution factors and limits are available in EN ISO 9223 [16]).

The corrosivity category (i.e., the corrosion rate) of the atmosphere can be determined in several ways:

- Experimental measurements obtained via exposed corrosion coupons;

- Experimental measurements utilizing resistance sensors;

- Estimations based on classified intervals of environmental parameters; 
- Calculation of corrosion losses from dose-response functions based on the knowledge of the required environmental parameters;

- Derived maps of the environment's corrosion aggressiveness.

The method of determining atmospheric corrosivity via exposed corrosion coupons directly captures the conditions at the considered site but is also highly demanding in terms of time. An alternative is to measure the environment's corrosivity via resistance sensors; however, these are usually designed to be used only in inside areas [17-19]. The most used and easily accessible methods for determining the corrosivity of the atmosphere, i.e., for estimating the corrosion rate $r_{c o r r}$ after 1 year of exposure, is the use of previously derived regression formulas, notably dose-response functions. These formulas were obtained for individual types of metals based on long-term experimental evaluations $[15,16,20,21]$. For carbon steel, it is possible to use one of the following dose-response functions (the same function can also be used for weathering steel):

(A). Dose-response function according to EN ISO 9223 [16]

The corrosion loss for carbon steel after 1 year of exposure is governed by the following empirical formula:

$$
r_{\text {corr }}=1.77 \cdot P_{d}^{0.52} \cdot e^{0.02 \cdot R H} \cdot e^{f_{s t}}+0.102 \cdot S_{d}^{0.62} \cdot e^{0.033 \cdot R H+0.04 \cdot T}
$$

where $f_{s t}$ is defined as $f_{s t}=0.15 \cdot(T-10)$, assuming that the average air temperature is below $10{ }^{\circ} \mathrm{C}$, otherwise the equation is defined as $f_{s t}=-0.054 \cdot(T-10) ; P_{d}$ is the average annual deposition of $\mathrm{SO}_{2}\left(\mathrm{mg} /\left(\mathrm{m}^{2} \cdot \mathrm{d}\right)\right) ; S_{d}$ is the average annual deposition of $\mathrm{Cl}^{-}\left(\mathrm{mg} /\left(\mathrm{m}^{2} \cdot \mathrm{d}\right)\right) ; T$ is the average annual temperature $\left({ }^{\circ} \mathrm{C}\right)$, and $R H$ is the average annual relative humidity $(\%)$.

(B). Dose-response function according to experimental tests from the UN/ECE ICP project on the Effect on Materials [20]

The UN/ECE ICP project was carried out between 1987 and 1995 [20]. The program shows that the corrosion loss of weathering steel can be estimated using the following empirical formula:

$$
r_{\text {corr }}=34 \cdot P_{d}^{0.33} \cdot e^{0.02 \cdot R H} \cdot e^{f_{s t}}
$$

where $f_{s t}$ is defined as $f_{s t}=0.059 \cdot(T-10)$, assuming that the average air temperature is below $10^{\circ} \mathrm{C}$, otherwise the equation is defined as $f_{s t}=-0.036 \cdot(T-10) ; P_{d}$ is the average annual deposition of $\mathrm{SO}_{2}$ $\left(\mathrm{mg} /\left(\mathrm{m}^{2} \cdot \mathrm{d}\right)\right) ; T$ is the average annual temperature, and $R H$ is the average annual relative humidity $(\%)$.

(C). Dose-response function according to experimental tests from the Multi-Assess program [21]

This program involved the placement of corrosion coupons at 50 test sites in Europe [21]. The samples (coupons) used to estimate corrosion losses considered significantly more environmental parameters than the equation listed above. The experimental test period already includes a significant drop in the primary corrosion stimulator in the air, notably sulfur dioxide. Based on this program, the corrosion loss of carbon steel can be predicted using the following empirical formula [21]:

$$
r_{\text {corr }}=29.1+\left(21.7+1.39 \cdot P_{d}^{0.6} \cdot R H_{60} \cdot e^{f_{s t}}+1.29 \cdot R A I N \cdot\left[H^{+}\right]+0.593 \cdot P M_{10}\right)
$$

where $f_{\text {st }}$ is defined as $f_{\text {st }}=0.15 \cdot(T-10)$, assuming that the average air temperature is below $10{ }^{\circ} \mathrm{C}$, otherwise the equation is defined as $f_{s t}=-0.054 \cdot(T-10) ; P_{d}$. is the average annual deposition of $\mathrm{SO}_{2}\left(\mathrm{mg} /\left(\mathrm{m}^{2} . \mathrm{d}\right)\right) ; S_{d}$ is the average annual deposition of $\mathrm{Cl}^{-}\left(\mathrm{mg} /\left(\mathrm{m}^{2} . \mathrm{d}\right)\right) ; R A I N$ is the average annual precipitation (mm); $R H_{60}$ is the average relative humidity (\%); $\mathrm{H}^{+}$is the average annual $\mathrm{pH}$ of precipitation, and $P M_{10}$ is the average annual concentration of dust particles (maximum diameter of $10 \mu \mathrm{m})\left(\mu \mathrm{g} / \mathrm{m}^{3}\right)$.

The corrosion losses calculated using the prediction models listed above were compared to the actual corrosion losses of carbon steel determined in 2005/06, 2008/09, and 2011/12 within the 
UN/ECE ICP program for atmospheric stations in Europe (Figure 1). It is important to mention that mathematical prediction models are mere approximations, that they are simplified, and are burdened with significant insecurities. However, the values listed in the figure indicate that the simplified formulas take into account the trend dependency rather well, but the results do exhibit a significant variance. In addition to the insecurities arising from the use of a specific prediction model, the variability of the predicted corrosion rates is also significantly affted by the random and variable nature of environmental parameters, which form input parameters in the appropriate dose-response functions.

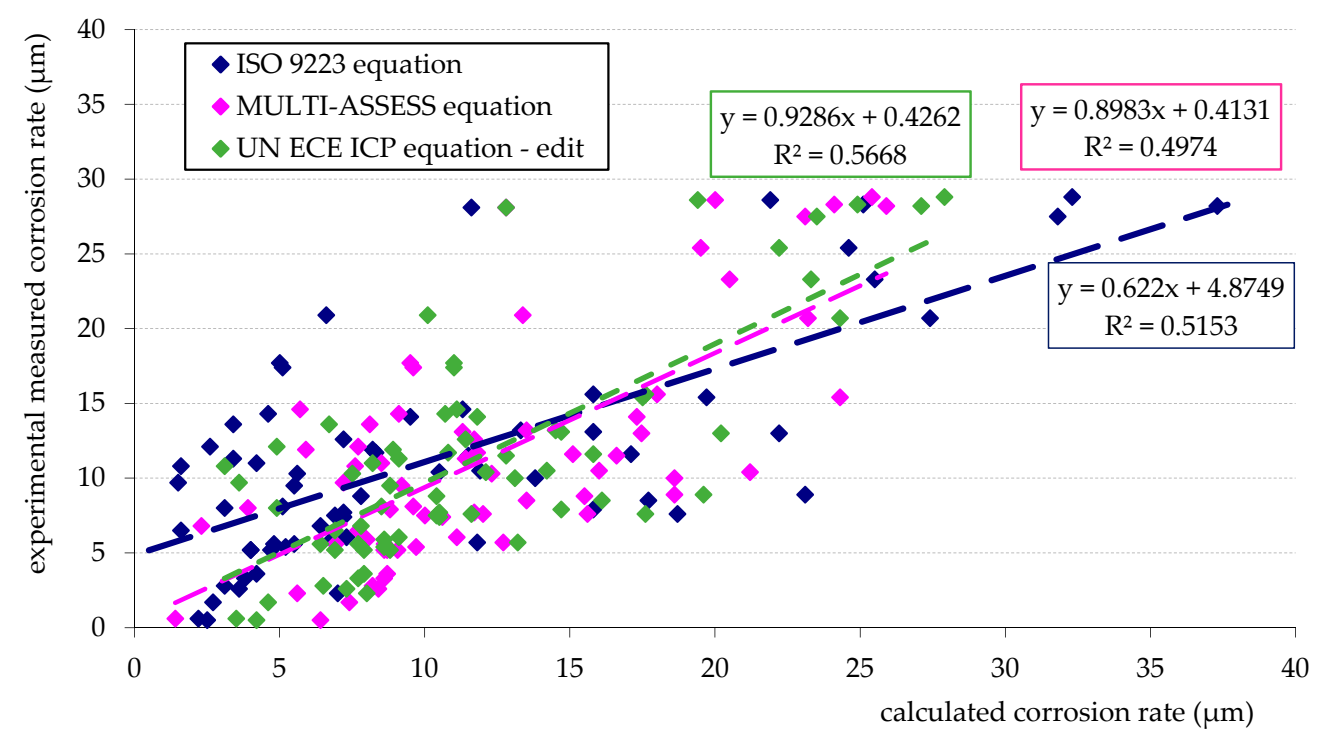

Figure 1. Corrosion losses calculated according selected dose-response function and experimental measured corrosion losses on atmospheric stations in Europe [14].

The article introduces and evaluates a stochastic approach to predictive models, which allows us to consider the random and variable nature of the input environmental parameters with sufficient accuracies, while also respecting the recommendations arising from long-running corrosion programs. The article also provides the results of sensitivity analyses that can be used to evaluate the specific impacts of individual corrosion agents on corrosion damage to structures. Special attention was also paid to sensitivity analysis focusing on an assessment of the impact of chloride deposition on corrosion damage to steel bridge structures. The analysis utilized data obtained from experimental measurements of deposition rates of chlorides in the vicinity of roads operated in the Czech Republic.

The main objectives of the article can be summarized in the following points:

- A procedure for stochastic processing of long-term measured environmental data;

- Introduction of a probabilistic prediction model for calculation of annual corrosion loses;

- Verification of suitable equations (so-called dose-response functions) for probabilistic prediction models of corrosion damage of steel structures in the vicinity of roads;

- Influence of individual environmental parameters on corrosion damage;

- A study focused on the specifics of corrosion damage to steel structures near roads where de-icing salts are used.

Probabilistic approaches are increasingly used to assess the reliability of building structures [22]. Using probabilistic methods, it is possible to directly take into account the random variability of input variables in the calculation. Typical random variables are material characteristics (especially the yield strength in structural steel) and individual loads acting on the structure (dead and live loads, snow, wind, and temperature loads, or traffic loads). The influence of the environment is a specific action, 
which manifests itself in steel structures mainly by their corrosion damage. Accurate prediction of corrosion damage will provide structural engineers and researchers with the necessary data to evaluate the durability of building structures [1-3]. Probabilistic calculations also make it possible to evaluate the impact of specific environmental factors. This can be used effectively in the design of a suitable corrosion protection system and the planning of long-term maintenance and repairs. The use can be expected both for steel structures with traditional corrosion protection by means of coatings and for structures designed from weathering steel [10]. A prediction of corrosion rates is also needed to evaluate the durability of reinforced concrete structures [4].

\section{Statistical Analysis of Environmental Parameters and Calculation of Selected Prediction Models Using Probabilistic Approach}

\subsection{Statistical Analysis—General Information}

The values of environmental parameters can be obtained via long-term measurements or from available databases of hydrometeorological institutes, e.g., the online databases of the Czech Hydrometeorological Institute for the Czech Republic [23]. The statistical evaluation of environmental data and their subsequent introduction into stochastic prediction models is provided below for the selected site of Kopisty (Czech Republic). Climatic parameters at Kopisty have been tracked by the specialized SVÚOM Ltd. worksite in Prague since 1969. The scope and quantity of the measured data were sufficient to perform statistical analysis. The data used originated from the timeframe 1969 to 2016.

In order to determine the expected range of the specific environmental parameter that will correspond to the final period of the data range, it was necessary to perform a statistical analysis for the measured data, while taking into account their random variable nature as well as their growth trends in the sequence. Regression analysis of the dataset for the last year in the data sequence was used to determine the average value of the environmental parameter. Furthermore, a 95\% prediction interval was determined, delimiting the area containing $95 \%$ of the measured data $[23,24]$. The borders of the $95 \%$ prediction strip allow us to specify the 2.5 and/or $97.5 \%$ quantiles of the distribution. The obtained equations for regression curves can be used to predict the value of the tracked environmental parameter also for the years that follow up on those in the data sequence.

The upper and lower limits (i.e., the bounding curves) of the prediction interval can be determined using the following formula [24]:

$$
y_{\max (\min )}=y_{r} \pm T_{0.95} \cdot S E \sqrt{1+\frac{1}{n}+\frac{\left(X-X_{m}\right)^{2}}{S S_{x x}}} .
$$

where $y_{r}$ is the mean of the parameters on the $y$-axis; $T_{0.95}$ is the $97.5 \%$ quantile of Student's $t$-distribution; $S E$ is the mean error of the average; $n$ is the number of examined values on the $x$-axis; $X_{m}$ is the mean, and $S S_{x x}$ is the sum of the squares of the deviations of the value $x$.

The statistical parameters listed above can be used to determine the mean $m_{x}$ and the standard deviation $s_{x}$ of the probabilistic density distribution for the tracked parameter. If a probability distribution were to be created from the whole dataset (as opposed to a mere extrapolation for the examined year in the data sequence), the statistical parameters $m_{x}$ and $s_{x}$ would not reflect the time trend of the changes to the tracked parameters (e.g., related to the gradual increase in temperatures), and there could be a significant impact on the resulting estimate of corrosion loss via prediction models.

Regression analysis and prediction intervals were calculated for all necessary climatic parameters, which had values that have been gradually changing over the past decades. For probability analysis, it is expected that the monitored climatic parameters have a normal (or lognormal) distribution. The obtained probability distributions are expressed using bounded histograms for the purposes of the following simulation calculations; the domain is restricted by the limit values of $+3 s_{x}$ to $-3 s_{x}$, as recommended in the literature [25]. The subsequent sections of the article (Sections 2.1.1 and 2.1.2) 
provide details regarding the statistical analysis of the primary stimulators for atmospheric corrosion (sulfur dioxide and chlorides) that enter the prediction models as per Equations (4)-(6). Similar analyses were also carried out for other parameters that entered the prediction models.

\subsubsection{Statistical Analysis-Annual Average Deposition Rate of $\mathrm{SO}_{2}$}

The annual average deposition rate of the concentration of sulfur dioxide in the air experienced a significant change over the past 50 years [26,27]. Figure 2 displays the monitored long-term deposition rate of sulfur dioxide for the selected site of Kopisty.

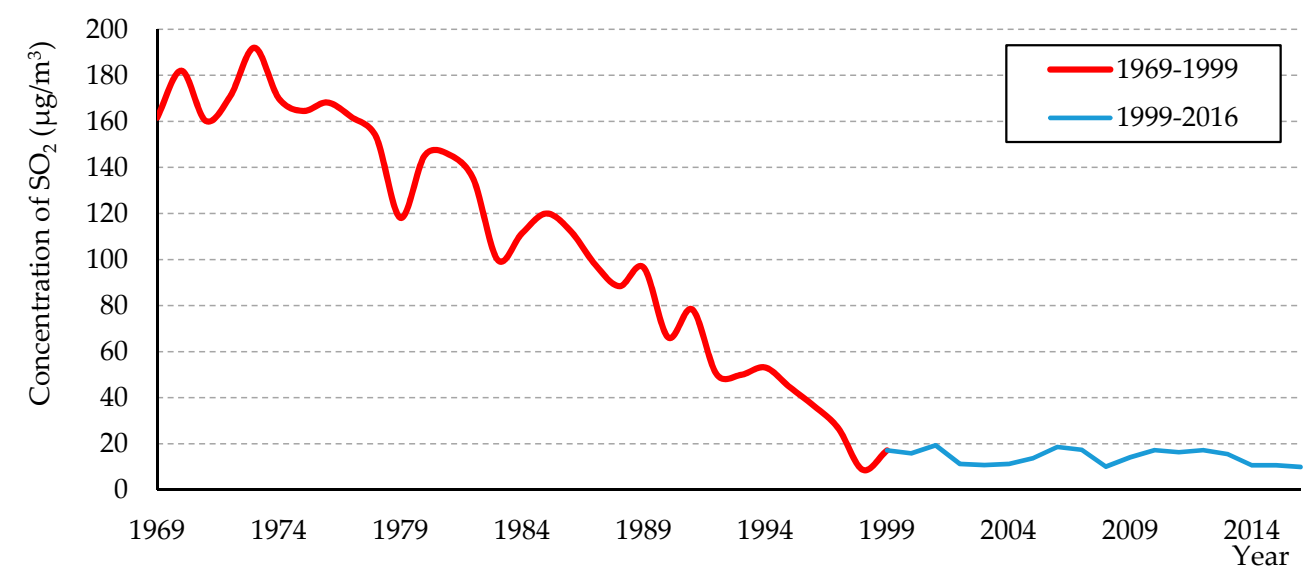

Figure 2. Annual average concentration of sulfur dioxide in locality Kopisty (Czech Republic).

The concentration of sulfur dioxide shown in Figure 2 illustrates a significant change in the average annual values depending on the tracked period. If the values from 1969-1998 were to be included in the prediction model for estimating corrosion loss at the end of the time series, the final predicted value of corrosion loss would have been significantly different. To statistically analyze the data and determine prediction models and the distribution of probability density for the deposition rate of sulfur dioxide, only data points obtained after 1998 were included from the dataset. The course of the linear regression exhibits a slight drop of the mean value, see Figure 3. Figure 4 displays the distribution of the probability density for the end point of the time series (obtained via the HistAn tool [28]).

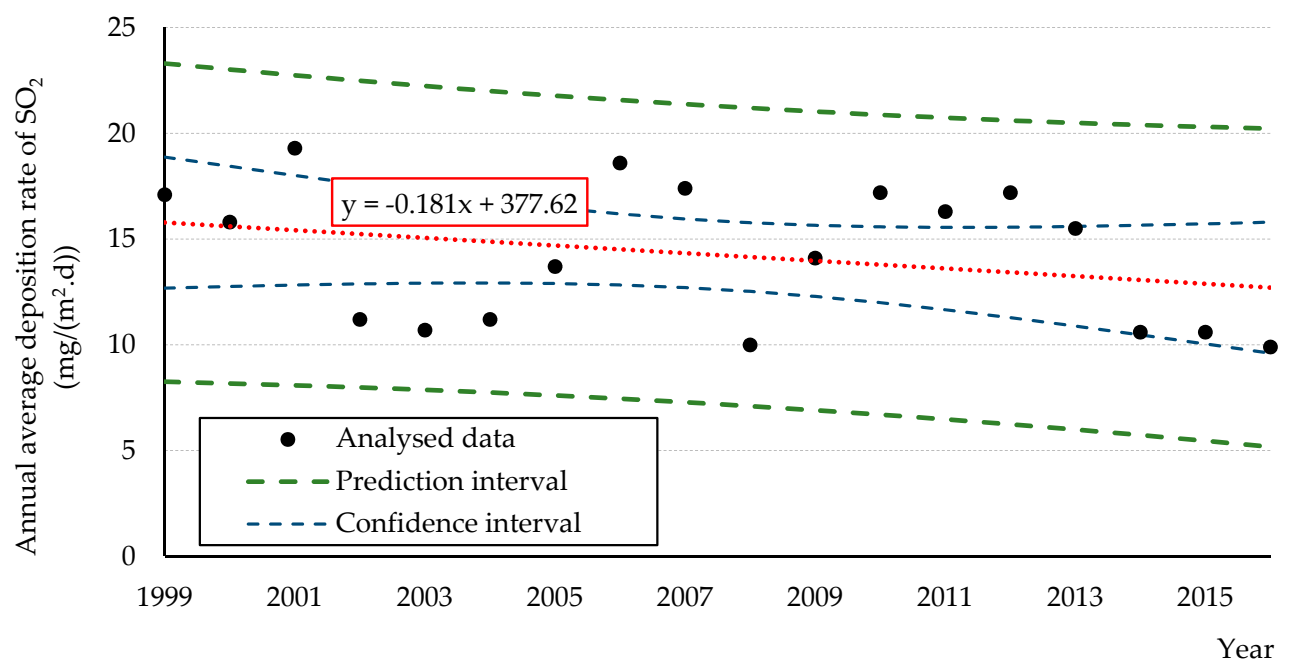

Figure 3. Annual average deposition rate of sulfur dioxide after 1998 in locality Kopisty (Czech Republic) - regression analysis and prediction intervals. 


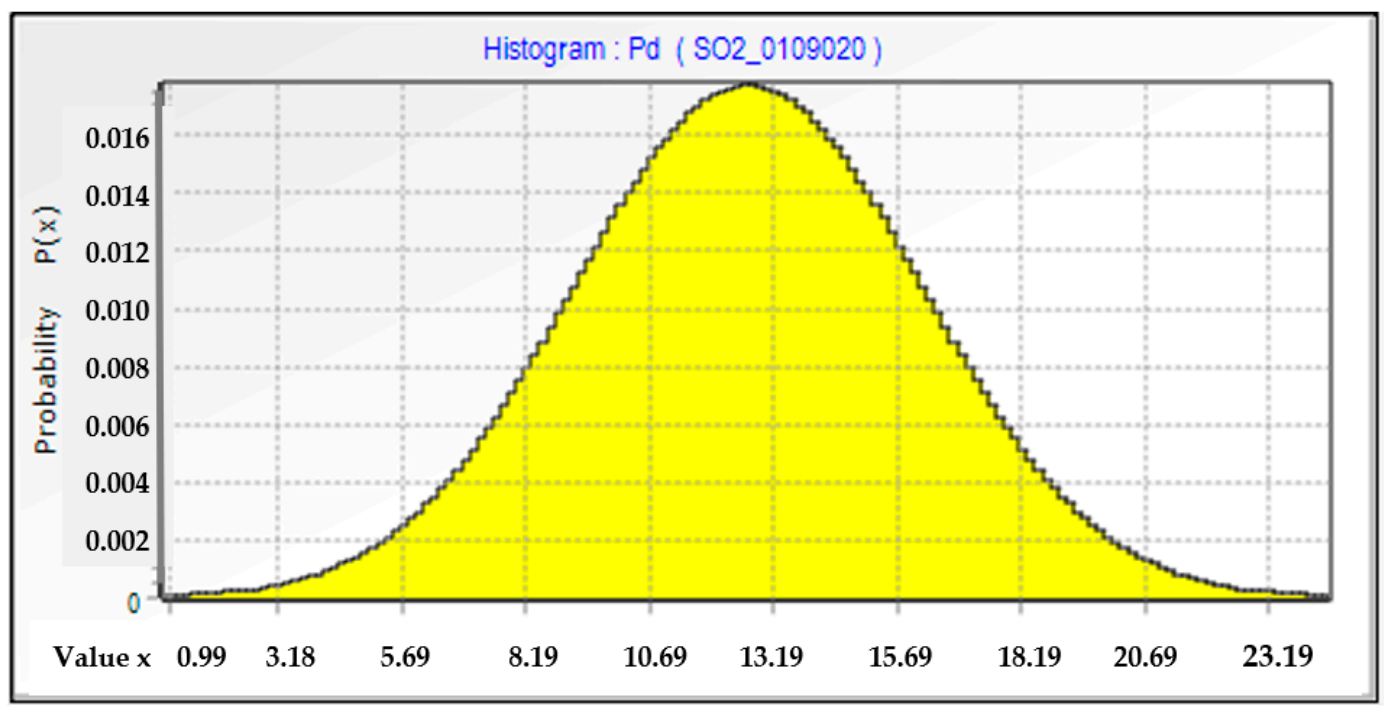

Figure 4. Normal distribution of probability density function-annual average deposition rate of $\mathrm{SO}_{2}$ $\left(\mathrm{mg} /\left(\mathrm{m}^{2} \cdot \mathrm{d}\right)\right)$ for locality Kopisty and year 2016.

\subsubsection{Statistical Analysis-Annual Average Deposition Rate of $\mathrm{Cl}^{-}$}

The deposition rate of chlorides in the air can be ascertained using the methods described in EN ISO $9225[26,27,29]$. Data on the dry deposition of chlorides are currently in short supply for the Czech Republic, and this applies especially for the surroundings of prominent road connections. When constructing the corrosion models, it was possible to indirectly use the finding that dust particles $P M_{10}$ contain, among other elements, approximately $7 \mathrm{wt. \%}$ of chlorides [20]. This assumption, however, cannot be used for microclimates in the vicinity of roads, where the deposition rate of chlorides is higher [30-32]. Experimentally determined quantities of dust particles $P M_{10}$ in the air are mostly expressed in $\left(\mathrm{mg} / \mathrm{m}^{3}\right)$. The prediction models receive chloride deposition rates expressed in $\left(\mathrm{mg} / \mathrm{m}^{2}\right)$. There is no clearly defined way of converting values from the former units to the latter. However, it is possible to make use of the dependency discovered in the experimental measurement of deposition and concentration of dust sediments (Figure 5) [21]. This experimental measurement led to a proposed formula that we used to establish the deposition rate of chlorides:

$$
P M_{10, \mathrm{dep}}=\frac{72.6}{100} P M_{10}
$$

where $P M_{10, \text { dep }}$ is the deposition rate of airborne dust particles in the air $\left(\mu \mathrm{g} /\left(\mathrm{cm}^{2} . \mathrm{month}\right)\right)$ and $P M_{10}$ is the concentration of airborne dust particles in the air $\left(\mu \mathrm{g} / \mathrm{m}^{3}\right)$.
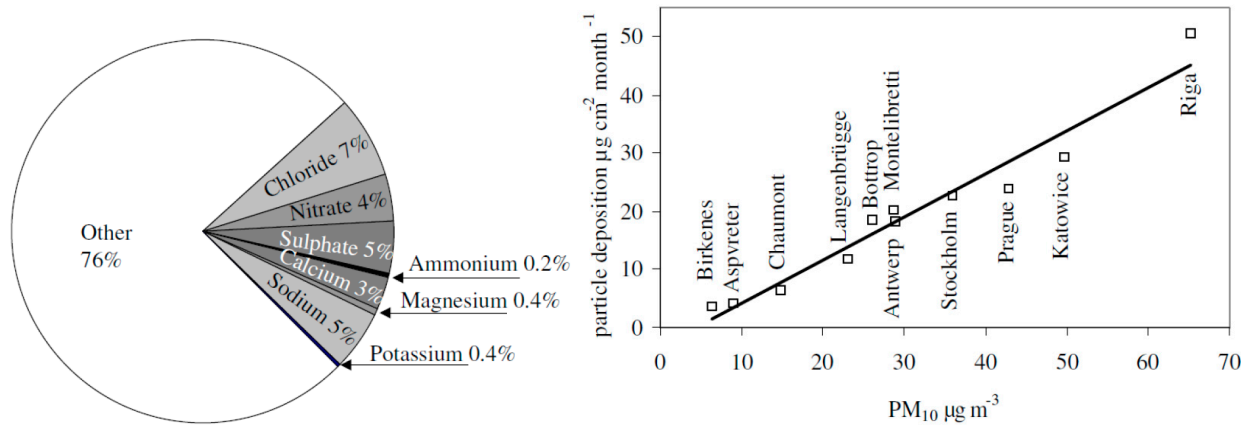

Figure 5. Experimental measured values of $\mathrm{PM}_{10}$ in the air-experimental program UN/ECE ICP [21]. 
The statistical analysis for the deposition rate of chlorides calculated from the deposition $P M_{10}$ at Kopisty is provided in Figures 6 and 7.

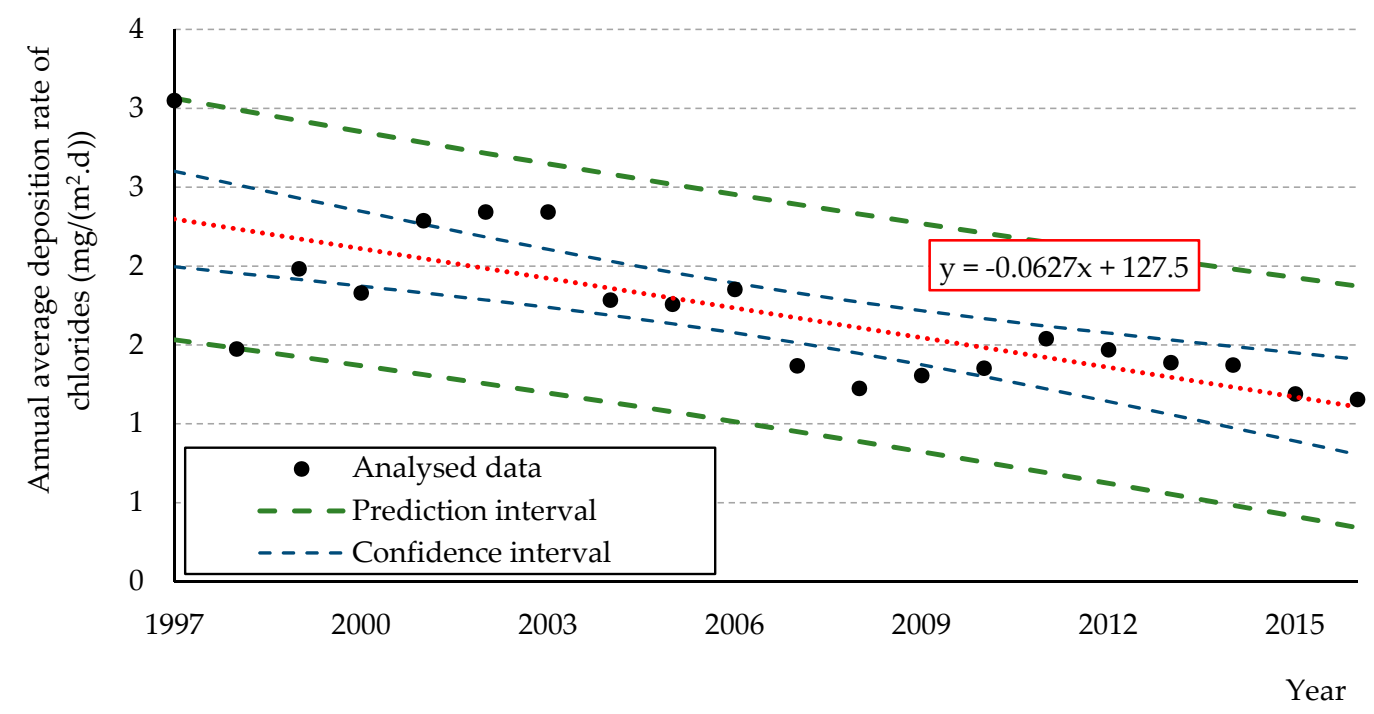

Figure 6. Annual average deposition rate of chlorides in locality Kopisty (Czech Republic)—regression analysis and prediction intervals.

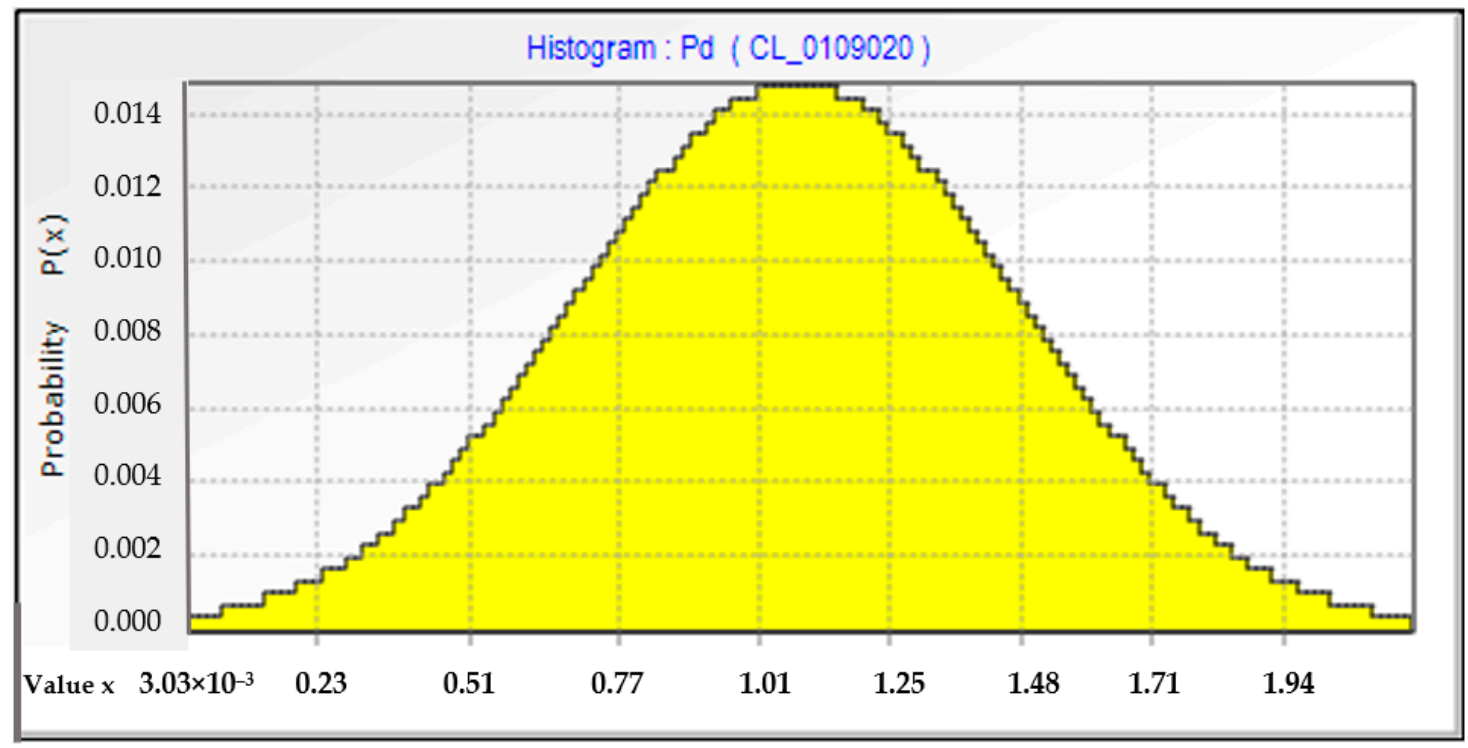

Figure 7. Normal distribution of probability density function-annual average deposition rate of chlorides $\left(\mathrm{mg} /\left(\mathrm{m}^{2} . \mathrm{d}\right)\right)$ for locality Kopisty in 2016.

\subsection{Calculation of Selected Prediction Models Using Probabilistic Approach}

The probabilistic analysis was carried out in the ProbCalc tool using the DOProC method [20,23]. The source code implementing the prediction models was programmed in Delphi. The source code was then imported into the ProbCalc computational module in the form of a DLL library. This procedure was used primarily in order to handle the different analytical formulas used by the model when the average annual temperature was above or below $10^{\circ} \mathrm{C}$ (see Formulas (4)-(6)). Individual random variables were assigned the appropriate probability density distribution obtained via statistical analysis for the values corresponding to the final year in the data series. The characteristics of individual distributions of random variables for climatic parameters are provided in Table 1 (maximum and minimum - limit values of the bounded histogram). 
Table 1. Basic characteristics of histograms of environmental parameters in locality Kopisty.

\begin{tabular}{cccccc}
\hline Parameters & Distribution & Maximum & Minimum & $m_{\boldsymbol{x}}$ & $s_{\boldsymbol{x}}$ \\
\hline$T\left({ }^{\circ} \mathrm{C}\right)$ & & 11.66 & 7.76 & 9.71 & 0.65 \\
$R H(\%)$ & & 85.45 & 69.01 & 77.23 & 2.74 \\
$P_{\mathrm{d}}\left(\mathrm{mg} /\left(\mathrm{m}^{2} \cdot \mathrm{d}\right)\right)$ & & 23.20 & 2.08 & 12.64 & 3.52 \\
$S_{\mathrm{d}}\left(\mathrm{mg} /\left(\mathrm{m}^{2} \cdot \mathrm{d}\right)\right)$ & normal & 2.25 & 0.00 & 1.08 & 0.39 \\
$P M_{10}\left(\mathrm{mg} /\left(\mathrm{m}^{3}\right)\right)$ & & 44.42 & 0.00 & 21.95 & 7.49 \\
$R A I N(\mathrm{~mm})$ & & 854.22 & 54.96 & 454.59 & 133.21 \\
$p H(-)$ & 7.71 & 3.93 & 5.82 & 0.63 \\
\hline
\end{tabular}

\subsection{Results of Probabilistic Calculation of Prediction Models}

ProbCalc used interval optimization [18-20] for the individual prediction models as per Formulas (4)-(6). This procedure speeds up the computation and reduces the number of computational steps, while retaining a sufficient accuracy of the computation. The resulting histograms for the Kopisty locality and individual prediction models are provided in Figures 8-10.

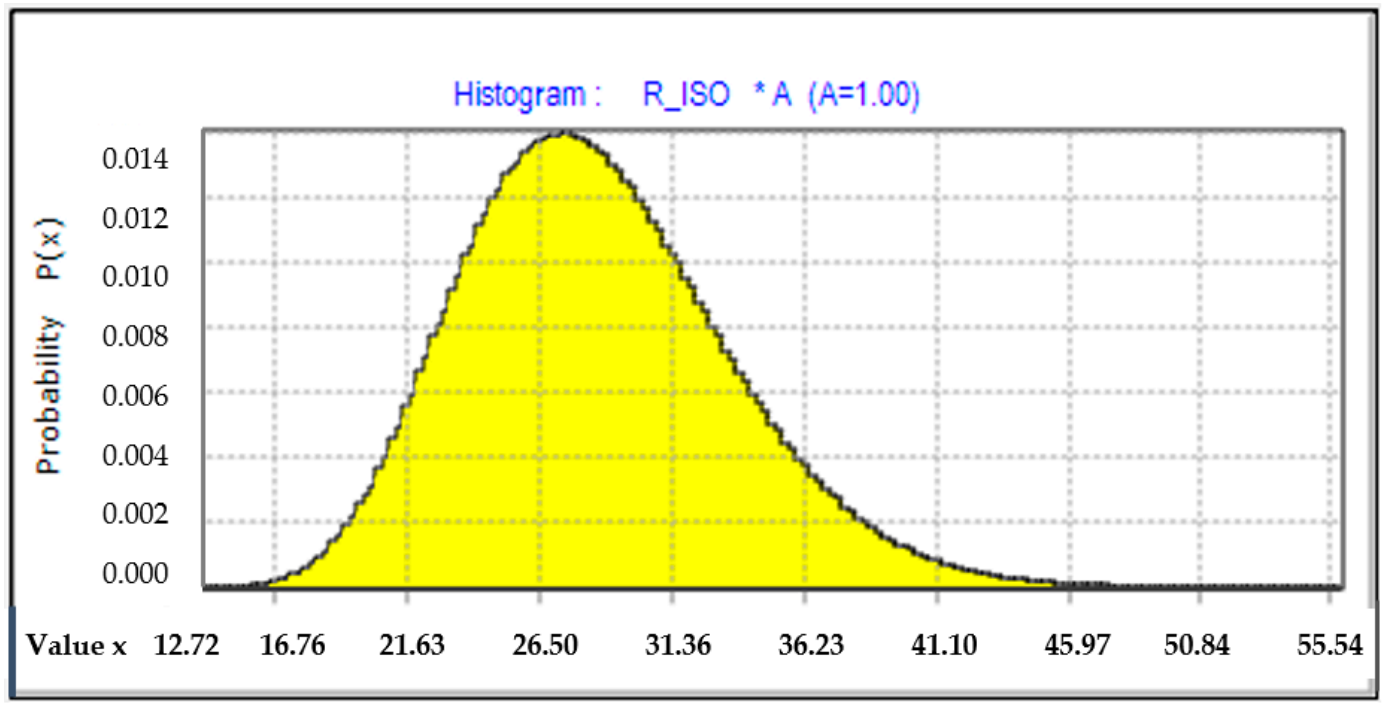

Figure 8. Function $r_{\text {corr }}(\mu \mathrm{m})$ for locality Kopisty—prediction model according to Equation (4).

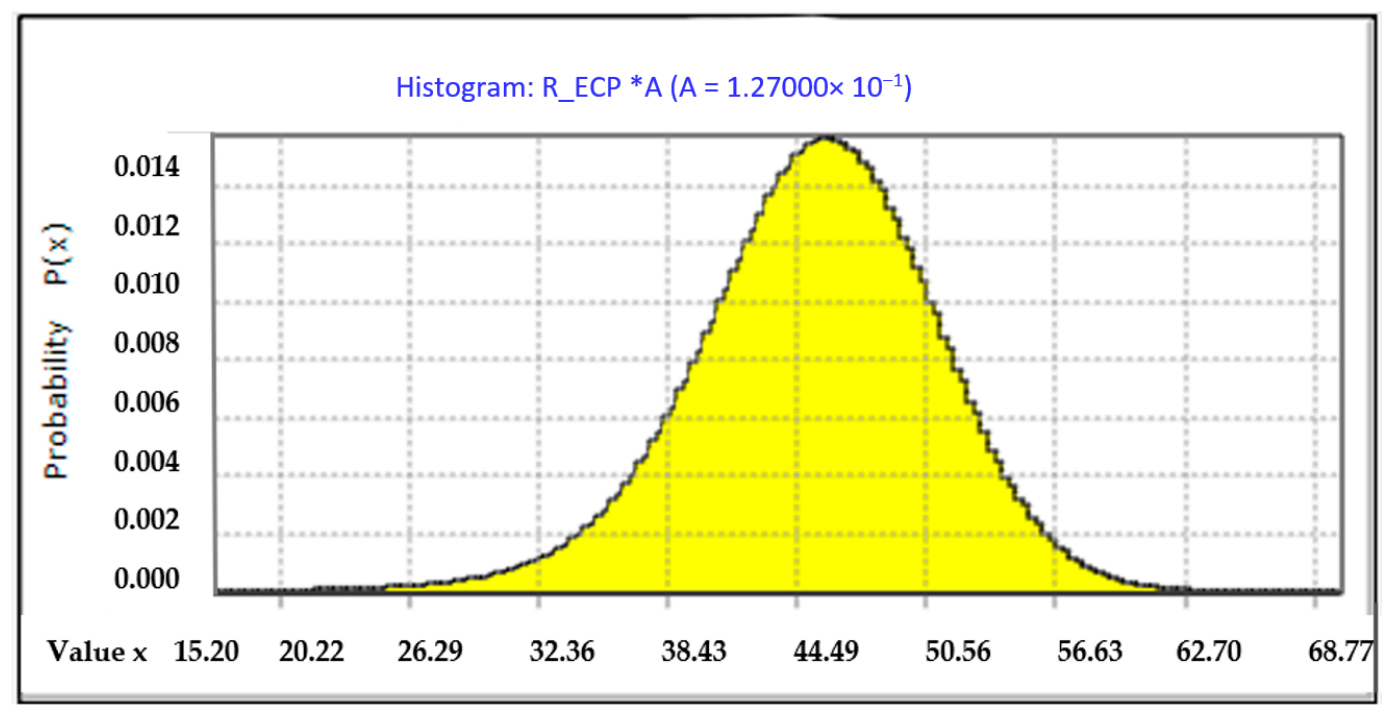

Figure 9. Function $r_{\text {corr }}(\mu \mathrm{m})$ for locality Kopisty—prediction model according to Equation (5). 


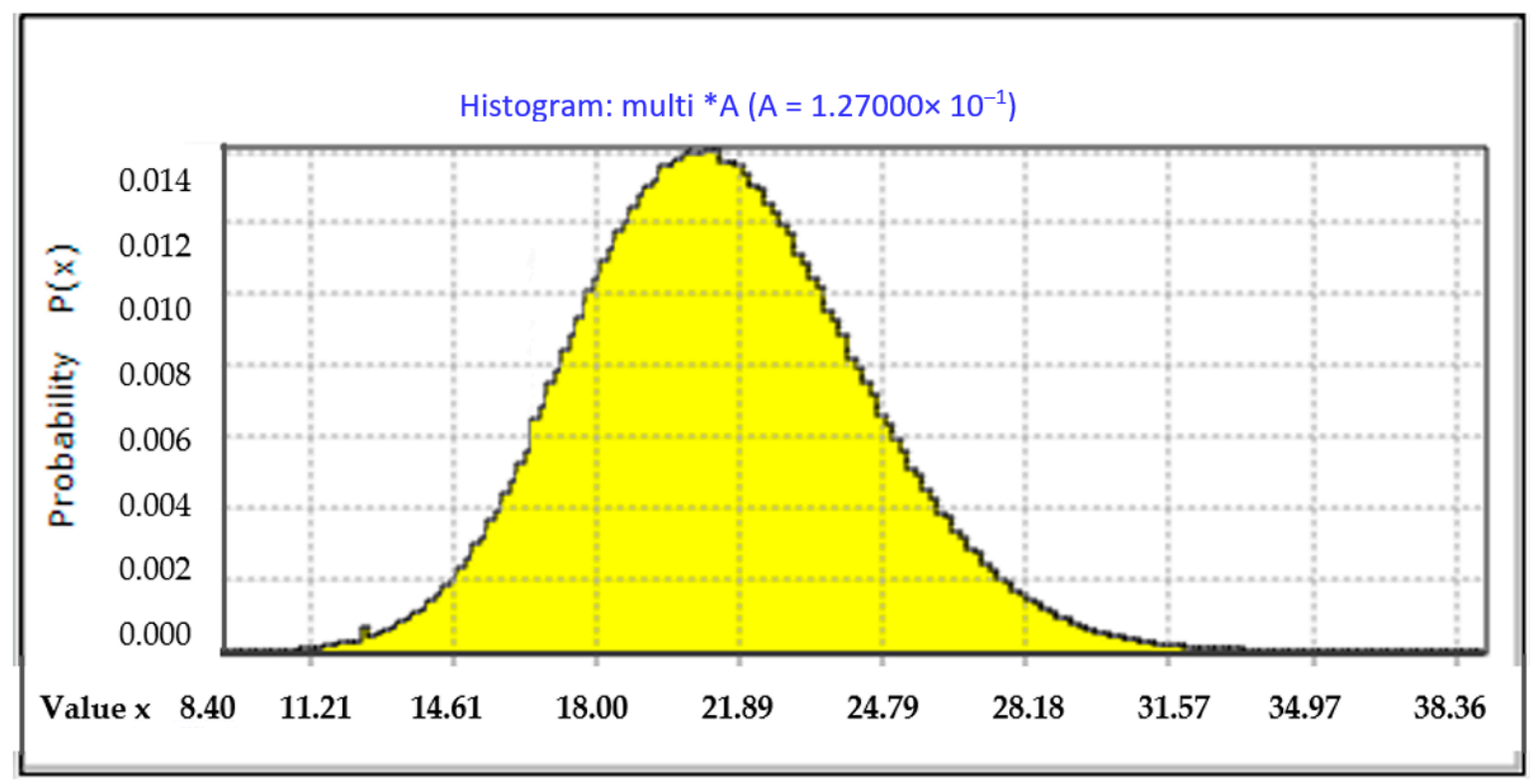

Figure 10. Function $r_{\text {corr }}(\mu \mathrm{m})$ for locality Kopisty—prediction model according to Equation (6).

The basic characteristics (mean $m_{x}$, standard deviation $s_{x}$, and variation coefficient $v_{x}$ ) for individual functions $r_{c o r r}$ determined via ProbCalc are provided in Table 2.

Table 2. Basic characteristics of histograms of function $r_{\text {corr }}$.

\begin{tabular}{cccccc}
\hline Locality & Parameters & $\boldsymbol{m}_{\mathbf{x}}$ & $\boldsymbol{s}_{\mathbf{x}}$ & $\boldsymbol{v}_{\mathbf{x}}$ & $\boldsymbol{m}_{\mathbf{x}} / \boldsymbol{r}_{\text {corr }}$ \\
\hline \multirow{4}{*}{ Kopisty } & ISO 9223 & 30.74 & 4.89 & 0.159 & 1.37 \\
& UN/ECE ICP & 45.37 & 5.58 & 0.123 & 2.02 \\
& Multi-Assess & 20.92 & 3.33 & 0.159 & 0.93 \\
& $r_{\text {corr }}$ from exposition 2015/2016 & 24.16 & - & - & - \\
\hline
\end{tabular}

The prediction models used for probability calculations demonstrate significant differences in the resulting values of corrosion losses. It is important to note that the results only apply to free exposure and not to microclimatic areas in the vicinity of bridge structures. The values obtained from the prediction models differ due to the fact of considering different atmospheric parameters that affect the corrosion processes on the surfaces of metals.

When using Equation (6) according to the Multi-Assess program, the lowest mean value of corrosion loss was obtained. This value was the one that was closest to the experimentally determined corrosion loss at Kopisty, which was $24.16 \mu \mathrm{m}$ in 2015/2016 and $20.77 \mu \mathrm{m}$ in 2016/2017. Based on the compared formulas, Equation (6) contains the most atmospheric parameters, which arguably increases the accuracy of the result. Equation (4) from EN ISO 9223 is more conservative compared to (6), yet the experimentally measured corrosion loss $r_{c o r r}$ still remains in the expected range predicted by the model, see Figure 10. Equation (5) resulted, based on the UN/ECE ICP, in the highest mean corrosion loss; the value is nearly double the experimentally obtained result. Equation (5) contains only three environmental parameters and completely neglects the impact of chlorides. Hence, only Equations (4) and (6) seem to be suitable for probabilistic prediction models of corrosion damage that consider the impact of chlorides, whereas Equation (4) provides the more conservative result. A similar finding has also been confirmed at other measuring sites in the Czech Republic. In the opinion of the authors of the article, it is also possible to use the probabilistic approach using Equation (4) or Equation (6) for other similar localities in the range of areas listed in $[20,21]$. 


\section{Sensitivity Analysis of Selected Prediction Model}

Sensitivity analysis can be used to determine the effect of individual variables entering the computational model on the monitored output parameter [33-35]. A simplified analysis can be carried out in the form of a parametric study utilizing analytical formulas that define the relationship between input values and the output parameter [35]. Since the inputs of the prediction model are random variables, the recommended procedure for sensitivity analysis is to use probabilistic methods $[27,33]$.

The article lists the results of the sensitivity analysis obtained in ProbCalc [28]. The sensitivity analysis was carried out in order to determine the corrosion rate after 1 year of exposure as per the prediction model defined in Equation (4). The selected prediction model is the only one out of the considered set that directly includes the impact of the deposition of chlorides on the corrosion rate of steel after 1 year of exposure. The prediction model is also part of the EN ISO 9223 standard. The suitability of the model has also been experimentally verified-see Section 2 . The input parameters for the selected prediction model are the actual measured values of average annual environmental parameters at the given site (for this article, we considered the data obtained at the Kopisty site) with the appropriate probability density distribution (Table 1).

To evaluate the sensitivity of the impact of input environmental parameters on the corrosion rate after 1 year of exposure, a sensitivity factor $k_{\mathrm{i}}(\%)$ defined by the formula below was used [33,34]:

$$
k_{i}=100 \frac{v_{y j}^{2}}{v_{y}^{2}}
$$

where $v_{y j}$ is the variation coefficient of the output (all input values except for the investigated one corresponded to the mean value) and $v_{y}$ is the variation coefficient of the output for random variables corresponding to all input parameters. The greater the value of the sensitivity factor, the greater the sensitivity of the output value to changes in the given input parameter. In the ProbCalc software, a total of five analyses were calculated by probabilistic calculation using the DLL library, which differed in how the input parameters were represented. The first model considers all input parameters to be random variables, while in the other models, only one of the input parameters is a variable, and the others are fixed to the value of their mean. The resulting characteristics of the calculated probability densities of the corrosion rate obtained via sensitivity analysis after 1 year of exposition are provided in Table 3.

Table 3. Corrosion rate after 1 year of exposure: basic characteristics of the statistical distribution (input data for the Kopisty locality).

\begin{tabular}{ccccccc}
\hline Model of Analysis & Variable Parameter & Maximum & Minimum & $\boldsymbol{m}_{\boldsymbol{x}}$ & $\boldsymbol{s}_{\boldsymbol{x}}$ & $\boldsymbol{v}_{\boldsymbol{x}}$ \\
\hline Model No. 1 & $T, R H, P_{\mathrm{d}}, S_{\mathrm{d}}$ & 54.53 & 13.36 & 30.74 & 4.89 & 0.159 \\
Model No. 2 & $T$ & 33.07 & 25.15 & 30.94 & 1.85 & 0.060 \\
Model No. 3 & $R H$ & 36.95 & 27.17 & 31.73 & 1.81 & 0.057 \\
Model No. 4 & $P_{\mathrm{d}}$ & 43.83 & 20.60 & 31.39 & 4.26 & 0.136 \\
Model No. 5 & $S_{\mathrm{d}}$ & 32.66 & 30.84 & 31.69 & 0.38 & 0.012 \\
\hline
\end{tabular}

However, at the Kopisty side, the deposition rate of airborne chlorides was very low. In order to evaluate the increased effect of chlorides on the resulting value of corrosion losses specified after 1 year of exposure as per Equation (4), it is hence necessary to make use of the experimentally identified deposition rates of chlorides measured in the vicinity of roads. For the purposes of this article, data measured on a bridge structure in Ostrava were used. The deposition rate of chlorides was measured under the bridge deck on the abutment using the dry plate and wet candle methods (Figure 11). Experimentally obtained data were used to create a histogram applied in the probability analysis (Figure 12). To perform a comparison and evaluate the effect of chlorides, the other parameters entering the sensitivity analysis were kept the same as in the Kopisty site, as in the previous example 
(see Table 1). The input parameters for the probability density distribution of environmental parameters are provided in Table 4.

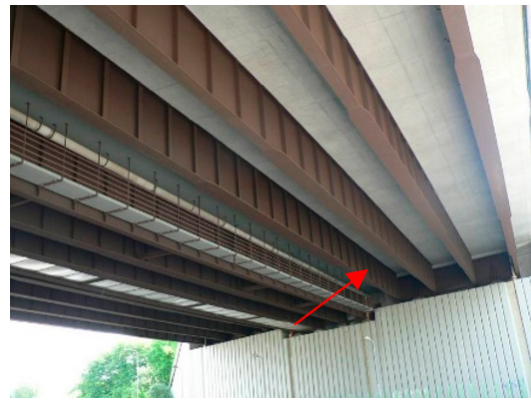

(a)

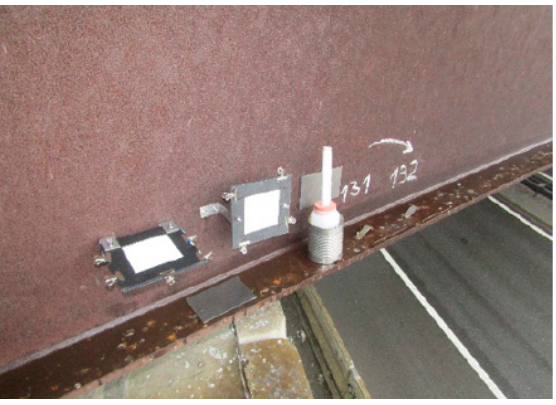

(b)

Figure 11. (a) Location of the measurement devices for the chloride deposition rate on the abutment on the bridge in Ostrava. (b) Details of the measuring devices-wet candle method and dry plate method.

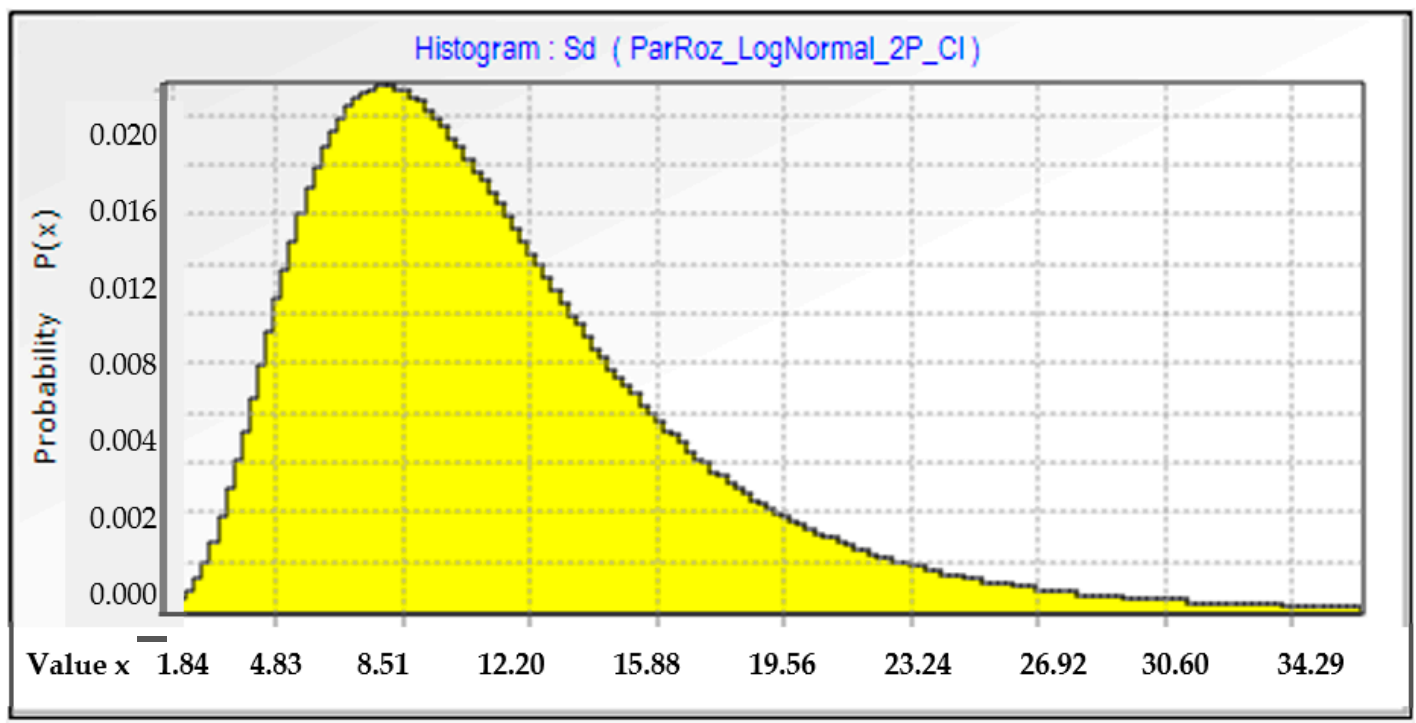

Figure 12. Normal distribution of probability density function-annual average deposition rate of chlorides for the locality Ostrava and in the year 2018/2019.

Table 4. Basic characteristics of histograms of environmental parameters for sensitivity analysis.

\begin{tabular}{cccccc}
\hline Parameters & Distribution & Maximum & Minimum & $\boldsymbol{m}_{x}$ & $\mathbf{s}_{\boldsymbol{x}}$ \\
\hline$T\left({ }^{\circ} \mathrm{C}\right)$ & & 11.66 & 7.76 & 9.71 & 0.65 \\
$R H(\%)$ & normal parametric & 85.45 & 69.01 & 77.23 & 2.74 \\
$P_{\mathrm{d}}\left(\mathrm{mg} /\left(\mathrm{m}^{2} \cdot \mathrm{d}\right)\right)$ & & 23.20 & 2.08 & 12.64 & 3.52 \\
$S_{\mathrm{d}}\left(\mathrm{mg} /\left(\mathrm{m}^{2} \cdot \mathrm{d}\right)\right)$ & 2 parameter log-normal parametric & 35.74 & 1.81 & 11.34 & 5.85 \\
\hline
\end{tabular}

\section{Results of Sensitivity Analysis}

The results of the sensitivity analysis (i.e., the sensitivity factors), taking into account the input parameters from Table 1, are provided on Figure 13. Among the environmental parameters obtained via long-term measurements at the Kopisty site, the one with the greatest impact on the corrosion rate after 1 year of exposure was the deposition rate of sulfur dioxide $\mathrm{SO}_{2}$ (Figure 13a). On the other hand, the smallest impact was associated with the deposition rate of chlorides; indeed, the deposition rate of chlorides was very low at the Kopisty site (the atmospheric station was not located in an area with intensive road traffic). 


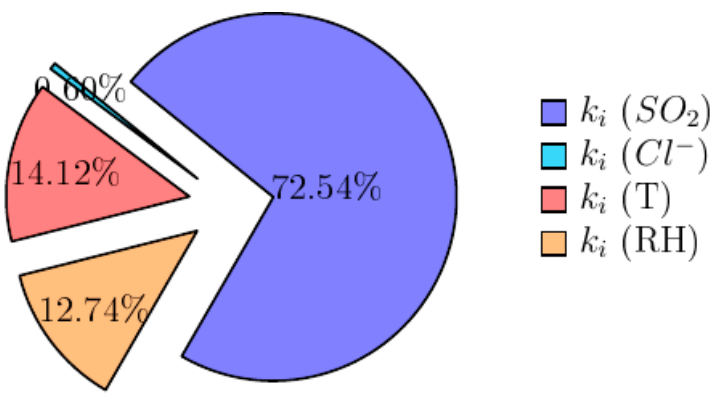

(a) $S_{\mathrm{d}, \mathrm{c}}=1.08 \mathrm{mg} /\left(\mathrm{m}^{2} . \mathrm{d}\right)$

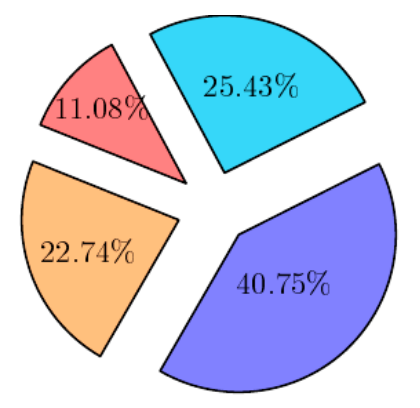

(c) $S_{\mathrm{d}, \mathrm{c}}=22.68 \mathrm{mg} /\left(\mathrm{m}^{2} . \mathrm{d}\right)$

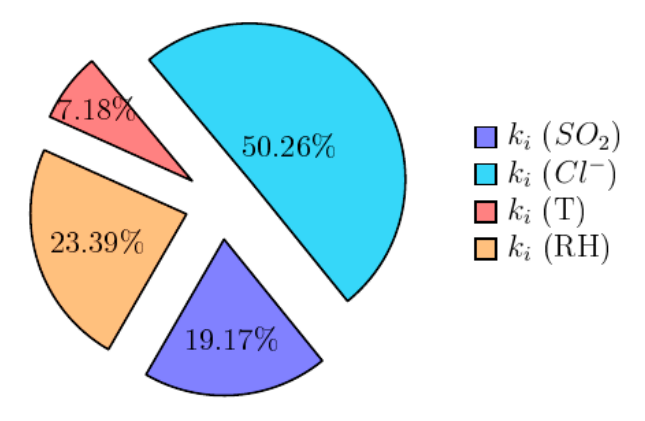

(e) $S_{\mathrm{d}, \mathrm{c}}=68.04 \mathrm{mg} /\left(\mathrm{m}^{2} . \mathrm{d}\right)$

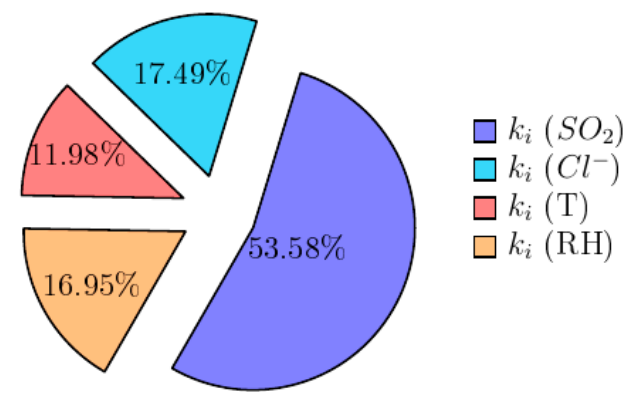

(b) $S_{\mathrm{d}, \mathrm{c}}=11.34 \mathrm{mg} /\left(\mathrm{m}^{2} . \mathrm{d}\right)$

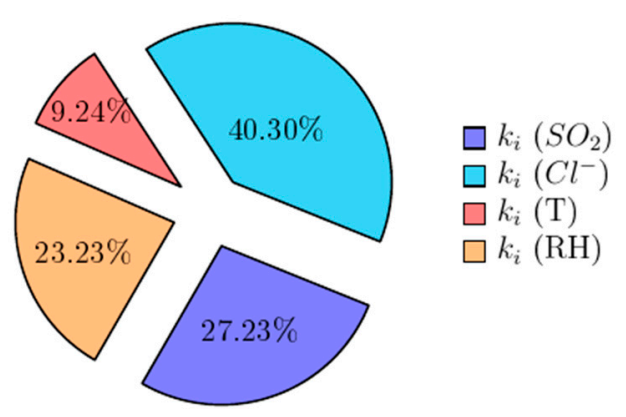

(d) $S_{\mathrm{d}, \mathrm{c}}=45.36 \mathrm{mg} /\left(\mathrm{m}^{2} . \mathrm{d}\right)$

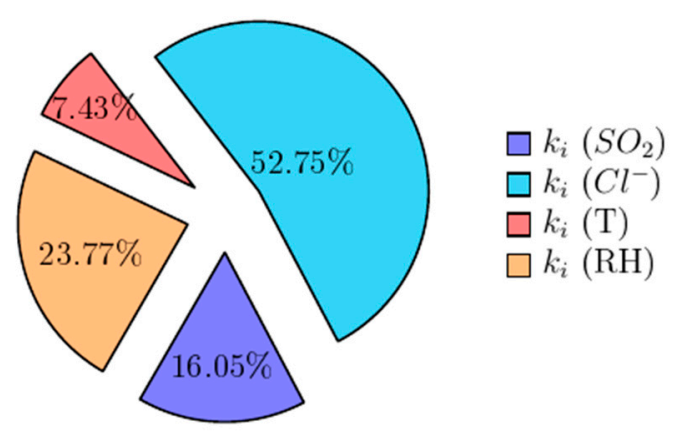

(f) $S_{\mathrm{d}, \mathrm{c}}=90.72 \mathrm{mg} /\left(\mathrm{m}^{2} . \mathrm{d}\right)$

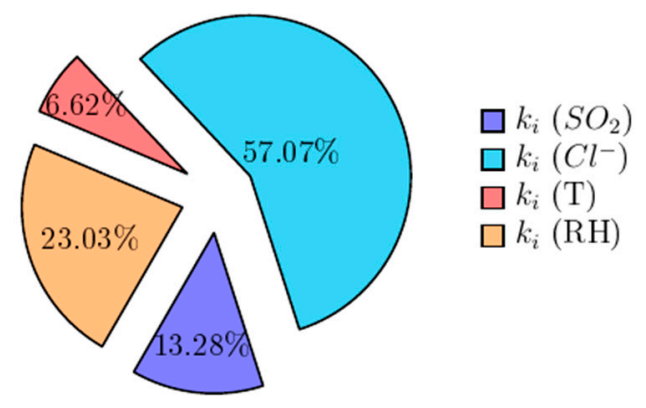

(g) $S_{\mathrm{d}, \mathrm{c}}=113.40 \mathrm{mg} /\left(\mathrm{m}^{2} . \mathrm{d}\right)$

Figure 13. Sensitivity factors $k_{\mathrm{i}}$ according to Equation (6) for locality Kopisty and dose-response function (4).

The effect of chlorides was significant when the sensitivity analysis takes into account the value of the deposition rate of chlorides that matched the actually measured values on the bridge structure in Ostrava, see Figure 13b. In particular, the sensitivity factor grew from a negligible 0.7 to $17.5 \%$. 
The value of experimentally identified annual average deposition rate of chlorides in Ostrava, however, does not reach values that would have a completely dominant impact on the resulting corrosion rate after 1 year of exposure for the given combination of climatic parameters. Due to the fact of this, a sensitivity analysis was also carried out for two to ten times the annual average deposition rates of chlorides measured on the bridge structure in Ostrava. The dose-response function listed in EN ISO 9223 was derived under the assumption of the average annual deposition rate of chlorides being between 0.4 and $760.5 \mathrm{mg} /\left(\mathrm{m}^{2} . \mathrm{d}\right)$. Ten times the experimentally determined deposition rate of chlorides at the bridge in Ostrava, amounting to $S_{\mathrm{d}, \mathrm{c}}=113.40 \mathrm{mg} /\left(\mathrm{m}^{2} . \mathrm{d}\right)$, is still significantly below the upper limit of the values used to derive the dose-response function [12]. That is why sensitivity analysis was also applied to higher values of chloride deposition (with a maximum corresponding to ten times the measured deposition rate), which all remained in the range of validity of the dose-response function (4).

Sensitivity analysis was carried out for the prediction model as per Equation (4) listed under EN ISO 9223, which is the only one out of the considered equations to consider the direct impact of chlorides. The impact of chlorides is also taken into account in Equation (6), but there, it is derived by converting from the experimental program and by using the relationship between the average annual deposition rate $P M_{10, \text { dep }}$ and the annual average concentration $P M_{10}$ in the air. Based on the sensitivity analysis, the deposition rate of sulfur dioxide had the greatest impact on the corrosion rate. However, if the higher deposition rate of chlorides corresponding to the values measured in the vicinity of bridge structures were to be included in the formula, the impact of sulfur dioxide would be lower, and the impact of chlorides would be larger. A higher deposition of chlorides also leads to a higher impact of relative air humidity. The values obtained from the sensitivity analysis for the individual considered average deposition rates of chlorides (amounting to two to ten times the values determined in the experimental measurements in Ostrava) are provided in Table 5 (where $S_{d}$ is the annual average deposition rate of chlorides; $k_{i}-S_{d}$ is the sensitivity factor for the deposition rate of chlorides; $k_{i}-P_{d}$ is the sensitivity factor for sulfur dioxide; $k_{i}-R H$ is the sensitivity factor for relative humidity, and $k_{i}-T$ is the sensitivity factor for temperature).

Table 5. Sensitivity factor $k_{i}[\%]$ for individual annual average values of chloride deposition rate.

\begin{tabular}{ccccc}
\hline$S_{\boldsymbol{d}}\left(\mathbf{m g} /\left(\mathbf{m}^{\mathbf{2}} \cdot \mathbf{d}\right)\right)$ & $\boldsymbol{k}_{\boldsymbol{i}}-\boldsymbol{S}_{\boldsymbol{d}}$ & $\boldsymbol{k}_{\boldsymbol{i}}-\boldsymbol{P}_{\boldsymbol{d}}$ & $\boldsymbol{k}_{\boldsymbol{i}} \boldsymbol{- R H}$ & $\boldsymbol{k}_{\boldsymbol{i}} \boldsymbol{- T}$ \\
\hline 1.08 & 0.60 & 72.54 & 12.74 & 14.12 \\
11.34 & 17.49 & 53.58 & 16.95 & 11.98 \\
22.68 & 25.43 & 40.75 & 22.74 & 11.08 \\
45.36 & 39.80 & 26.71 & 22.71 & 8.72 \\
68.04 & 50.26 & 19.17 & 23.39 & 7.18 \\
90.72 & 52.75 & 16.05 & 23.77 & 7.44 \\
113.40 & 56.32 & 12.53 & 22.28 & 5.87 \\
\hline
\end{tabular}

Easier-to-navigate results can be obtained by graphically displaying the values of the sensitivity factor $k_{i}$ for individual investigated parameters depending on the size of the average annual deposition rate of chlorides (Figure 14).

Figure 14 clearly shows that as the average annual deposition rate of chlorides grows, so does its impact on the resulting value of the predicted corrosion loss as per Equation (4). This increased impact of chlorides can be expected primarily in microclimates near bridge structures. The impact of relative humidity also exhibited a slight growing trend. The impact of temperature on the resulting corrosion rate did not exhibit significant changes. It is important to note that the sensitivity analysis was carried out for the concrete combination of climatic parameters at the Kopisty site, and other combinations may lead to different ratios of the individual factors. 


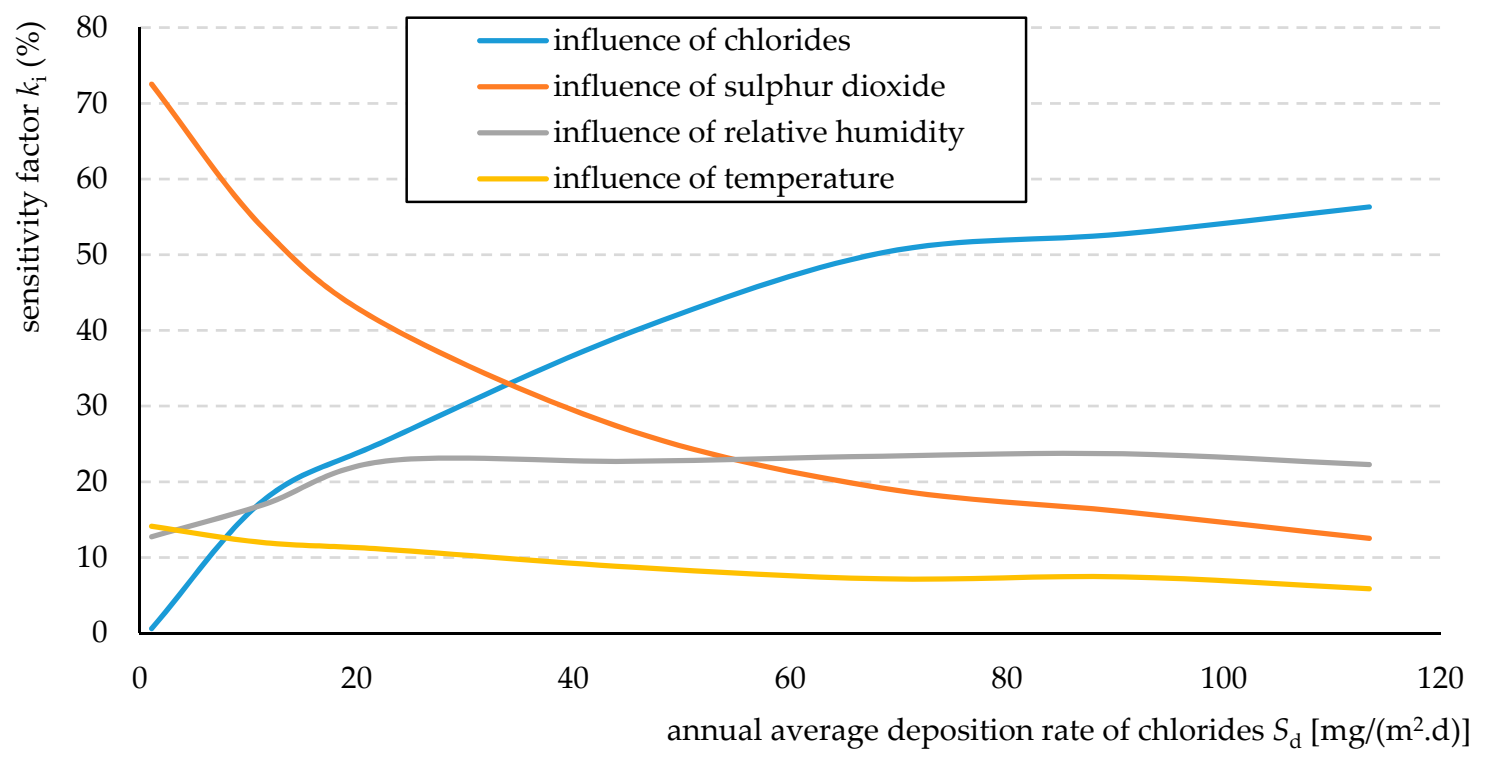

Figure 14. Sensitivity factors $k_{i}(\%)$ for individual environmental parameters.

\section{Conclusions}

The significant findings in this manuscript can be summarized in the following points:

- Environmental parameters affecting corrosion processes are random variables. It is, therefore, advantageous to use a probabilistic approach to predict corrosion damage;

- To accurately predict corrosion damage, it is necessary to analyze the measured data from a sufficiently long period. Stochastic models should reflect the observed time trends;

- Corrosion damage to steel structures in the vicinity of roads is significantly affected by the deposition rate of chlorides $[10,11,26,27]$. Using a stochastic approach, the effect of chloride deposition can be effectively evaluated;

- Dose-response functions given in EN ISO 9223 can be used to predict corrosion rates using a probabilistic approach.

Environmental parameters, which affect the corrosion processes on the surface of a metal, are random variables. It is, hence, not possible to predict the specific value of the corrosion rate unambiguously and deterministically for a selected site. The stochastic approach is better suited for such predictions, since it respects the natural variability of the environmental parameters. Statistical methods can be used to introduce development trends of individual random variables over time into prediction models. The use of the probabilistic approach also allows the performance of sensitivity analyses [33,34], which can be used to evaluate the impact of individual random variables on the corrosion rate after 1 year of exposure.

The prediction of annual corrosion losses based on probabilistic methods can be carried out via suitable dose-response functions [14-16]. Based on the analysis carried out in this article, the formula listed in EN ISO 9223 and the formula obtained from the extensive experimental Multi-Assess program seem to be the best suited for the prediction [21].

Sensitivity analysis demonstrated that the highest impact on the resulting corrosion rate after 1 year of exposure is caused by the deposition rate of sulfur dioxide. This finding is, however, only valid for sites that are not affected by intense road traffic. When the prediction models were enhanced with data capturing the actual deposition rates of chlorides in the vicinity of roads, the effect of sulfur dioxide dropped, while the effect of chlorides together with that of relative air humidity grew.

Structural engineers are obliged to design reliable structures that can fulfil their roles for the whole duration of their planned service life. Accurate prediction of corrosion aggressiveness of the 
environment near roads is one of the major inputs for the design of a suitable system of corrosion protection and for planning adequate maintenance and repair systems. Ensuring the long-term sustainability of newly designed as well as previously completed construction projects within the area of transport infrastructure brings significant economic as well as environmental benefits.

Author Contributions: Conceptualization, V.K. and M.K.; methodology, M.K., V.K., and K.K.; validation, V.K., M.K. and P.K.; investigation, M.K.; resources, K.K.; writing—original draft preparation, V.K. and M.K.; writing-review and editing, P.K. and K.K.; visualization, M.K.; supervision, V.K. and K.K.; project administration, P.K. All authors have read and agreed to the published version of the manuscript.

Funding: This research received no external funding or This research was funded by he Grant Agency of the Czech Republic grant number 18-07949S.

Acknowledgments: This article was achieved with the financial support of the Grant Agency of the Czech Republic (registration number of the project 18-07949S).

Conflicts of Interest: The authors declare no conflict of interest.

\section{References}

1. Urban, V.; Krivy, V.; Buchta, V. Corrosion Processes on Weathering Steel Railway Bridge in Prague. J. Teknol. 2016, 78. [CrossRef]

2. Konečný, P.; Lehner, P. Durability assessment of concrete bridge deck considering waterproof membrane and epoxy-coated reinforcement. Perspect. Sci. 2016, 7, 222-227. [CrossRef]

3. Strieška, M.; Koteš, P.; Sedmak, A. Decreasing bridge member's resistance due to reinforcement corrosion. Procedia Struct. Integr. 2018, 13, 1745-1750. [CrossRef]

4. Odrobiňák, J.; Gocál, J. Experimental measurement of structural steel corrosion. Procedia Structural Integrity 2018, 13, 1947-1954. [CrossRef]

5. Koteš, P.; Brodňan, M.; Bahleda, F. Diagnostics of Corrosion on a Real Bridge Structure. Adv. Mater. Sci. Eng. 2016, 2016. Article ID 2125604. [CrossRef]

6. Wallinder, I.O.; Bahar, B.; Leygraf, C.; Tidblad, J. Modelling and mapping of copper runoff for Europe. J. Environ. Monit. 2007, 9, 66-73. [CrossRef]

7. Vestreng, V.; Myhre, G.; Fagerli, H.; Reis, S.; Tarrasón, L. Twenty-five years of continuous sulphur dioxide emission reduction in Europe. Atmos. Chem. Phys. Discuss. 2007, 7, 3663-3681. [CrossRef]

8. Houska, C. Deicing Salt-Recognizing the Corrosion Threat; TMR Consulting: Pittsburgh, PA, USA, 2008.

9. Lottes, S.A.; Bojanowski, C. Computer Modeling and Analysis of Truck Generated Salt-Spray Transport Near Bridges; Argonne National Laboratory: McLean, VA, USA, 2013.

10. Křivý, V.; Urban, V.; Kreislová, K. Development and failures of corrosion layers on typical surfaces of weathering steel bridges. Eng. Fail. Anal. 2016, 69, 147-160. [CrossRef]

11. Kubzova, M.; Křivý, V.; Kreislová, K. Influence of Chloride Deposition on Corrosion Products. Procedia Eng. 2017, 192, 504-509. [CrossRef]

12. Ohya, M.; Takebe, M.; Hirose, N.; Matsuura, H.; Imai, A. Estimation of Air-borne Salts by Use of Wind Direction and Speed Sata. Corros. Eng. 2014, 63, 566-569. [CrossRef]

13. Zhang, Q.; Wu, J.; Wang, J.; Zheng, W.; Chen, J.; Li, A. Corrosion behavior of weathering steel in marine atmosphere. Mater. Chem. Phys. 2003, 77, 603-608. [CrossRef]

14. Kreislova, K.; Knotkova, D. Atmospheric Corrosion Aggressiveness and Methods of Atmospheric Corrosion Prediction; SVÚOM Ltd.: Prague, Czech Republic, 2014.

15. Kreislova, K.; Geiplova, H.; Bartak, Z.; Majtas, D. Atmospheric Corrosion Models. Mater. Corros. Prot. 2016, 61, 59-66. [CrossRef]

16. International Organization for Standardization. Corrosion of Metals and Alloys-Corrosivity of Atmospheres-Classification, Determination, and Estimation; ISO 9223; International Organization for Standardization: Geneva, Switzerland, 2012.

17. Kreislova, K.; Knotkova, G. Atmospheric Corrosion; SVÚOM Ltd.: Prague, Czech Republic, 2014; ISBN 978-80-87444-11-5.

18. Shinohara, T.; Motoda, S.-I.; Oshikawa, W. Evaluation of Corrosivity in Atmospheric Environment by ACM (Atmospheric Corrosion Monitor) Type Corrosion Sensor. Mater. Sci. Forum 2005, 475, 61-64. [CrossRef] 
19. Cook, M. The Challenge of Technical Standardization and Other Market Issues. In Proceedings of the Lectures of the 19th Hot-Dip Galvanizing Conference, Spindleruv Mlyn, Czech Republic, 2-4 October 2013.

20. Lauenberger-Minger, A.U.; Buchmann, B.; Faller, M.; Richner, P.; Zöbeli, M. Dose-response Functions for Weathering Steel, Copper and Zinc Obtained from a Four-year Exposure Program in Switzerland, A review. Corros. Sci. 2002, 44, 675-687. [CrossRef]

21. Multi-Assess Final Report. Available online: http://www.corr-institute.se/icp-materials/getfile.ashx?cid= 1044880\&cc $=3 \&$ refid $=2$ (accessed on 4 November 2020).

22. Krejsa, M.; Janas, P.; Krejsa, V. Software Application of the DOProC Method. Int. J. Math. Comput. Simul. 2014, 8, 121-126.

23. Czech Hydrometeorological Institute-ČHMÚ. Available online: https://portal.chmi.cz/ (accessed on 4 November 2020).

24. Olive, D.J. Prediction intervals for regression models. Comput. Stat. Data Anal. 2007, 51, 3115-3122. [CrossRef]

25. Marek, P.; Brozzetti, J.; Gustar, M.; Elishakoff, I. Probabilistic Assessment of Structures using Monte Carlo Simulations. Appl. Mech. Rev. 2002, 55, B31-B32. [CrossRef]

26. Křivý, V.; Kubzova, M.; Kreislová, K.; Urban, V. Characterization of Corrosion Products on Weathering Steel Bridges Influenced by Chloride Deposition. Metals 2017, 7, 336. [CrossRef]

27. Křivý, V.; Kubzova, M.; Konečný, P.; Kreislová, K. Corrosion Processes on Weathering Steel Bridges Influenced by Deposition of De-Icing Salts. Materials 2019, 12, 1089. [CrossRef]

28. Martin, K.; Janas, P.; Krejsa, V. ProbCalc-An Efficient Tool for Probabilistic Calculations. Adv. Mater. Res. 2014, 969, 302-307. [CrossRef]

29. International Organization for Standardization. Corrosion of Metals and Alloys-Corrosivity of Atmospheres-Measurement of Environmental Parameters Affecting Corrosivity of Atmospheres; ISO 9225; International Organization for Standardization: Geneva, Switzerland, 2012.

30. Yamaguchi, E. Maintenance of Weathering Steel Bridges. Steel Constr. Today Tomorrow 2015, 45, 12-15.

31. Iwasaki, E.; Nagato, T.; Yuasa, A.; Nishi, T. Scattering of Deicing Salt and Corrosion of Steel Bridges. J. Struct. Eng. 2012, 58A, 655-666.

32. Maruyama, K.; Kamasaki, S.; Tajima, K.; Aso, T. Local Corrosion Environment around Cross Section of a Plate Girder Bridge. In Resilient Structures and Sustainable Construction; ISEC Press: Fargo, ND, USA, 2017; ISBN 978-0-9960437-4-8.

33. Kleijnen, J.P.C. Experimental Design for Sensitivity Analysis, Optimization, and Validation of Simulation Models. In Handbook of Simulation; John Wiley and Sons: Hoboken, NJ, USA, 2007; pp. 173-223.

34. Yao, J.; Cheng, K. Discussion of sensitivity factors and dominating variable for design value method. KSCE J. Civ. Eng. 2016, 21, 37-44. [CrossRef]

35. Strieška, M. Influence of Corrosion on Reliability of Reinforced Concrete Structures. Master's Thesis, Department of Building Structures and Bridges, Faculty of Civil Engineering, University of Žilina, Žilina, Slovakia, 2019. (In Slovak).

Publisher's Note: MDPI stays neutral with regard to jurisdictional claims in published maps and institutional affiliations.

(C) 2020 by the authors. Licensee MDPI, Basel, Switzerland. This article is an open access article distributed under the terms and conditions of the Creative Commons Attribution (CC BY) license (http://creativecommons.org/licenses/by/4.0/). 